\title{
Attitude and behaviour of hospital workers on healthy diet and lifestyle in Eastern Turkey
}

\author{
Dilek Kusaslan Avci*, Huseyin Avni Sahin, Hatice Tuba Akbayram \\ Department of Family Medicine, Medical Faculty of Yuzuncu Yil University, Van, Turkey
}

\begin{abstract}
This research was conducted for the purpose of determining the healthy lifestyle behaviors of physicians, nurses and other hospital employees in Medical Faculty of Yuzuncu Yil University, Van, Eastern Turkey.

A total of 440 physicians, nurses and other hospital employees working in the University Hospital were invited to participate. Research data in this descriptive study were collected with a questionnaire covering; nutrition consuming frequency, nutrition consuming behaviour, general health condition, body height and weight, blood pressure, alcohol and cigarette consumption, exercise, socio demographic characteristics.

Smoking more than 10 cigarettes a day in smokers among physicians, nurses, and other employees were $83.3 \%, 76.7 \%$ and $46.9 \%$ respectively (p: 0.004). The highest rates of obesity were seen in physician $(20.9 \%)(\mathrm{p}=0.000)$. The highest rates of hypertension were seen in other employees $(24.3 \%)(p=0.000)$. Eating fast food daily among physicians, nurses, and other employees were $10.5 \%, 7.4 \%$ and $0 \%$ respectively (p: 0.000 ). $11 \%$ of females and $17.1 \%$ of male were doing regular exercise. Starting the day without having breakfast among female and male were $37.2 \%, 43.8 \%$ respectively.

As they are the role model for the rest of the population more time and care should be given to understand the reasons, so they may improve their attitudes regarding healthy diet and lifestyle.
\end{abstract}

Key Words: Healty diet, lifestyle, obesite, hypertension, exercise, health workers

\section{Introduction}

Non-smoking, a low Body Mass Index (BMI), being physically active, and adherence to a Mediterranean diet were associated with a lower disease burden. A prospective cohort study clearly shows the benefits of a healthy lifestyle. The disease burden among persons who never smoked, maintain a normal BMI, are not physically inactive, and adhere to a healthy diet is considerably lower than that of those who do not adhere to any of the healthy lifestyle behaviours and results in a minimum of two years longer life in good health. Each additional healthy lifestyle factor contributes significantly to a longer life in good health independent of the lifestyle score someone already has (1).

Some studies measured a disease-specific mortality or the incidence of a chronic disease. A combination of healthy lifestyle factors is associated with a lower cancer incidence and mortality, particularly in subtypes such as colorectal cancer, or pancreatic cancer $(2,3)$.

A study shows combined lifestyle factors healthy weight, high physical activity, non-smoking, limited alcohol consumption and a healthy dietare associated with a lower colorectal cancer incidence in European populations characterized by western lifestyles (4). It is related with a reduction of the risk of coronary heart disease, stroke, diabetes and dementia (5-8).

Therefore, it is increasingly important to investigate potentially modifiable factors that are related to living longer in good health. Unhealthy behaviours, such as being physically inactive, smoking, unhealthy diet and irregular nutrition are leading contributors to morbidity and mortality.

This is the descriptive qualitative research investigating physicians and nurses' healty diet, lifestyle behaviours and attitudes in Turkey.

This research was conducted for the purpose of determining the healthy lifestyle behaviors of physicians, nurses and other hospital employees in Medical Faculty of Yuzuncu Yil University, Van, Eastern Turkey.

\section{Materials and methods}

Sample characteristics: A total of 440 physicians, nurses and other hospital employees

This study was presented in 20.th WONCA Europe Conference, OP-207, 22-25 October,September 2015, İstanbul, Turkey. (Kuşaslan Avcı D., Şahin H.A., Akbayram H.T. Attitude and Behaviour of Hospital Workers on Healthy Diet.) 
working in the University Hospital were invited to participate.

The questionnaire was prepared by the researchers after review of the relevant international literature, and finalized following a pilot application prior to data collection.

Research data in this descriptive study were collected with a questionnaire covering; nutrition consuming frequency, nutrition consuming behaviour, general health condition, body height and weight, blood pressure, alcohol and cigarette consumption, exercise, socio demographic characteristics.

Of these, 430 responded to the questionnaire (response rate was $97.7 \%$ ).

Measurements: The blood pressure values of the individuals were obtained with a single measurement after they rested at least 15 minutes. A standard protocol was used for the measurement; it was ensured that the person is in a sitting position and the right arm of the person is naked as to allow for blood pressure. Systolic blood pressure (SBP) and diastolic blood pressure (DBP) were measured using a stethoscope and a sphygmomanometer. For the individuals who have not been diagnosed with hypertension before was diagnosed as "hypertension present" if average $\mathrm{SBP} \geq 140 \mathrm{mmHg}$ or average DBP $\geq 90 \mathrm{mmHg}$.

BMI, which handles weight and height together, was calculated using the formula weight $(\mathrm{kg})$ / height $(\mathrm{m})^{2}$. BMI is a cheap and non-invasive criterion in evaluating obesity. According to WHO, individuals with $\mathrm{BMI}<18.5$ are defined "low weighted", BMI=18.5-24.9 "normal weighted", BMI=25.0-29.9 "overweighted" and $\mathrm{BMI} \geq 30$ are defined as "obese"(9).

Self reported physical activity levels in the leisure time were asked. Information about intensity, duration and frequency of the physical activities were collected.
Data analysis: Statistical analyses were performed using SPSS v.18..Descriptive analyses accomplished. Chi square and Mann Whitney $U$ tests were used for comparisons. The level of significance was set at $\mathrm{p}$ $<0.05$.

Ethical consideration: Medical school of Yuzuncu Yil University Research Ethics Committee (REC/ REF: 01/11.12.2014) approved the study. All participants gave written consent prior to interview.

\section{Results}

Data were collected from a total of 430 hospital employees. Of these participants were $35 \%$ ( $\mathrm{n}=152$ physician), $37.9 \%(\mathrm{n}=163)$ nurses, $27.1 \%$ $(n=115)$ other hospital employees). Of the respondents were $40 \%(\mathrm{n}=172)$ female and $55.6 \%$ $(n=240)$ married. Of the respondent were $42.8 \%$ single and $55.8 \%$ married. Mean $( \pm S D)$ age of the respondents was $31.4 \pm 8.56$ years and ranged from 18 to 65 years. The mean Body Mass İndex (BMI) of the respondents was $24.6 \pm 4.03$.

Table 1 shows the sociodemographic characteristics of respondents.

Table 2 shows the data regarding to profession were found differences among among smoking, alcohol consumption, fast food consumption, BMI, blood pressure.

Our study showed that there was no significant relationship between profession and amount of alcohol consumption $(\mathrm{p}=0.222)$.

There was no significant relationship between profession $(50 \%$ in physicians, $64.4 \%$ in nurses, $47.8 \%$ in other hospital employees) and the presence of obesity in first-degree relatives of individuals $(\mathrm{p}=0.757)$.

Table 1. Sociodemographic characteristics of respondents $(\mathrm{n}=430)$

\begin{tabular}{llll}
\hline Characteristics & Physicians (\%) & Nurses $(\%)$ & Other hospital employees $(\%)$ \\
\hline Gender & & & \\
\hline Male & 69.7 & 70.7 & 77.4 \\
Female & 30.3 & 61.3 & 22.6 \\
\hline Mean Age & 29.4 & 29.3 & 36.8 \\
\hline Marital Status & & & \\
\hline Single & 53.3 & 48.5 & 20.9 \\
Married & 46.1 & 50.9 & 75.7 \\
\hline Mean BMI & 24.1 & 23.8 & 26.2 \\
\hline
\end{tabular}

East J Med Volume:21, Number:3, July-September/2016 
Table 2. Smoking, alcohol consumption, diet, exercise, BMI and blood pressure data according to profession

\begin{tabular}{|c|c|c|c|c|}
\hline & Physicians $(\%)$ & Nurses $(\%)$ & Other hospital employees $(\%)$ & $\mathrm{p}^{*}$ \\
\hline \multicolumn{5}{|l|}{ Smoking } \\
\hline Yes (among all the participants) & 27.6 & 34.4 & 46.9 & 0.004 \\
\hline $\begin{array}{l}\text { Daily smoking } \geq 10 \text { (among } \\
\text { the smokers) }\end{array}$ & 83.3 & 76.7 & 66.6 & 0.016 \\
\hline Alcohol consumption & & & & 0.035 \\
\hline Yes & 19.1 & 9.2 & 7 & \\
\hline Daily breakfast & & & & 0.687 \\
\hline No & 55.9 & 39.3 & 24.3 & \\
\hline Frequency of daily meals & & & & 0.069 \\
\hline Less than three times & 38.2 & 31.3 & 26.1 & \\
\hline Fast food consumption & & & & 0.000 \\
\hline Daily & 10.5 & 7.4 & 0 & \\
\hline One or two times per week & 38.2 & 33.1 & 32.2 & \\
\hline No & 1.3 & 4.9 & 7 & \\
\hline Regular Exercise & & & & 0.340 \\
\hline Yes & 13.2 & 13.5 & 18.3 & \\
\hline No exercise & 45.4 & 51.5 & 47.8 & \\
\hline BMI & & & & 0.000 \\
\hline Overweight and obesity & 39.8 & 26.3 & 58.2 & \\
\hline Obesity & 20.9 & 7.9 & 15.6 & \\
\hline Blood pressure & & & & 0.000 \\
\hline$\leq 120-80 \mathrm{mmhg}$ & 21.5 & 79.6 & 61.7 & \\
\hline Hypertansion & 10.45 & 18.5 & 24.3 & \\
\hline
\end{tabular}

${ }^{*}$ Chi square test.

When we look at the number of main meals consumed per day, $61.8 \%$ physicians, $68.7 \%$ nurses, $73.9 \%$ other employees were consuming three main meals a day $(\mathrm{p}=0.069)$.

In our research most commonly skipped meal was breakfast and the most common reason for skipping meals was not having time. Skipping the meals due to not having time to eat among physicians, nurses, and other employees were 34.9 $\%, 25.8 \%$ and $24.3 \%$ respectively (p: 0.039 ).

Table 3 shows the data regarding to gender were found differences among smoking, alcohol consumption, fast food consumption,BMI and blood pressure.

The study showed that there was no significant relationship between gender and amount of alcohol consumtion $(\mathrm{p}=0.566)$. Our study showed that $11 \%$ female and $17.1 \%$ male were doing regular exercise $(\mathrm{p}=0.256)$. Starting the day without having breakfast among female and male were $37.2 \%$ and $43.8 \%$ respectively and the rate ofnever skipping meals was $35.5 \%$ and $29.8 \%$ respectively $(\mathrm{p}=0.965) .11 \%$ of females and $17.1 \%$ of male were doing regular exercise $(p=0.340)$.
Starting the day without having breakfast among female and male were $37.2 \%, 43.8 \%$ respectively $(\mathrm{p}=0.167)$.

Table 4 shows ratio of the findings as determined by marital status differences among smoking, alcohol consumption, fast food consumption, BMI and blood pressure.

The results showed that there was no significant difference between single and married individuals according to amount of alcohol consumption $(p=0.872)$. Our study showed that $16.8 \%$ of the single and $12.5 \%$ of the married were doing regular exercise $(p=0.097)$. Starting the day without having breakfast among single and married were $51.6 \%$ and $33.3 \%$ respectively $(\mathrm{p}=0.064)$. Never skip meals among single and married were $22.8 \%$ and $38.8 \%$ respectively $(\mathrm{p}=0.064)$.

\section{Discussion}

In a study in Greece it was found that $38.6 \%$ of the physicians ( $40 \%$ of men; $37 \%$ of women) and $32 \%$ of nurses were currently smokers $(10,11)$. 
Table 3. Smoking, alcohol consumption, fast food consumption, BMI and blood pressure data according to gender

\begin{tabular}{|c|c|c|c|}
\hline & Female $(\%)$ & Male $(\%)$ & $\mathrm{p}^{*}$ \\
\hline \multicolumn{4}{|l|}{ Smoking } \\
\hline Yes (among all the participants) & 24.4 & 42.6 & 0.000 \\
\hline Smoking $\geq 10$ daily (among the smokers) & 18 & 32 & 0.000 \\
\hline Alcohol consumption & & & 0.000 \\
\hline Yes & 4.1 & 17.4 & \\
\hline Fast food consumption & & & 0.059 \\
\hline Daily & 4.1 & 8.1 & \\
\hline No & 7 & 2.3 & \\
\hline BMI & & & 0.015 \\
\hline Overweight and obesity & 23.8 & 54.6 & \\
\hline Obesity & 4.6 & 13.5 & \\
\hline Blood pressure & & & 0.000 \\
\hline$\leq 120-80 \mathrm{mmhg}$ & 85.4 & 70.9 & \\
\hline Hypertansion & 9.88 & 17.4 & \\
\hline
\end{tabular}

*Chi square test.

Table 4. Smoking, alcohol consumption, fast food consumption, BMI and blood pressure data according to marital status.

\begin{tabular}{llll}
\hline & Single $(\%)$ & Married $(\%)$ & $\mathrm{p}^{*}$ \\
\hline Smoking & & & 0.001 \\
\hline Yes (among all the participants) & 26.1 & 42.5 & 0.002 \\
Smoking $\geq 10$ daily (among the smokers) & 20 & 30.8 & 0.252 \\
\hline Alcohol consumption & & & 0.000 \\
\hline Yes & 16.8 & 8.3 & \\
\hline Fast food consumption & & & 0.000 \\
\hline Daily & 13 & 1.7 & \\
No & 2.7 & 5 & 0.977 \\
\hline BMI & & & 21.1 \\
\hline Overweight and obesity & 16.2 & 20.1 & \\
Obesity & 2 & & 74.8 \\
\hline Blood pressure & & 19.5 & \\
\hline$\leq 120-80$ mmh & 84.6 & & \\
Hypertansion & 6.9 & & \\
\hline
\end{tabular}

* Chi square test.

In a study in Ukraine smoking rate was found $32.5 \%$ in pediatricians, $37.5 \%$ in family physicians (12).

Our results show that an important part of physicians and nurses still smoke $(27.6 \%$ and $34.4 \%$ respectively). Smoking is highest in other employees, male and married. But, average consumed amount of smoking per day is highest in physicians, male and single. According to our study smoking rates of physicians, nurses and other health workers was higher than smoking rates of general population of Turkey.

In a large national study in USA, $15.4 \%$ of surgeons met diagnostic criteria for alcohol abuse or dependence (13). In a study (Chronic Diseases and Risk Factors Survey In Turkey), in total 87\% of the participants stated that they had never used alcohol. Only $13 \%$ of the participants used alcohol. While $23 \%$ of males drink alcohol, $4 \%$ of females drink alcohol (14). 
In our study, alcohol consumption in physicians, males and single are more common than other hospital workers. Our rates are low in alcohol consumption, due to common Islamic beliefs, the low demand of alcohol consumption and possible social pressures on this subject in our region.

In a study in Japan, the primary care physicians' exercise frequency was as follows: daily, $11.6 \%$; at least 2-3 times per week, $26.2 \%$ (15). In a study in nurses in Korea,the prevalence of regular exercise was the lowest $38.6 \%$ (16).

In a study in Turkey, $43.9 \%$ of the physicians stated that they never exercised, and $31.7 \%$ of them said that they participated in sportive activities occasionally (17). Compared with other studies in our study, hospital workers' exercise habits (especially in physicians, nurses, female and married) were found to be inadequate.

Our study showed eating fast food prevalance are more common in physicians, males and single. One tenth of the physicians eat fast food every day. Fast food eating rate of man two times higher than fast food eating rate of women. Also, fast food eating rate of single eight times higher than fast food eating rate of married. We could not find any research about this topic on physicians and nurses in the literature. Therefore, our data was not comperable.

In Puhl et al's study (18) respondents reported more mistrust of physicians who are overweight or obese, were less inclined to follow their medical advice, and were more likely to change providers if the physician was perceived to be overweight or obese, compared to normal-weight physicians who elicited significantly more favorable reactions. This study suggests that providers perceived to be overweight or obese may be vulnerable to biased attitudes from patients, and that providers' excess weight may negatively affect patients' perceptions of their credibility, level of trust and inclination to follow medical advice.

Accoring to WHO World Health Statistics 2014, $14 \%$ of famales, $10 \%$ of males are obese. In a study in USA, the prevalence of obesity was $35.5 \%$ among adult men and $35.8 \%$ among adult women (19). According to Canadian Health Measures Survey about $62.1 \%$ of the adult population is overweight (body mass index [BMI] $\geq 25 \mathrm{~kg} / \mathrm{m}^{2}$ ) and $24.3 \%$ is obese (BMI $\geq 30$ $\left.\mathrm{kg} / \mathrm{m}^{2}\right)(20)$.

In a cohort of nurses and midwives in Australia, $\mathrm{NZ}$ and the UK, of the total sample of nurses and midwives the majority $(61.87 \%)$ were outside the healthy weight range (overweight accounted for $32.81 \%$, obese for $24.73 \%$ and morbidly obese for $3.37 \%)$. Males were overweight $(45.22 \%)$ or obese
(22.84\%). Statistically significant differences were demonstrated between gender and BMI status $(p<0.001)$. Married nurses and midwives were the majority $(61.85 \%)$ fell in the overweight categories. The association between marital status and obesity was significant at the $1 \%$ level (21). In a study in Turkey prevalence of obesity defined as BMI $\geq 30 \mathrm{~kg} / \mathrm{m}^{2}, 15 \%$ in males and $29 \%$ in females (22).

We could not find any research for BMI measurement in physicians in the literature. Therefore, we can not compare our data. Our obesity rates showed that about one-fifth of the physicians are obese. Obesity in nurses were lower than nurses in other countries. Obesity rate of man was three times higher than obesity rate of women. Also, obesity rate of married was twenty times higher than obesity rate of single. The reason for these results may be the low sample counts.

Increased blood pressure is the leading risk factor for premature death, stroke and heart disease worldwide (23).

In a study it was shown that hypertension prevalance ( $\geq 140 \mathrm{mmh} \mathrm{SBP}$ and/or $\geq 90 \mathrm{mmhg}$ DBP) was lower in Canada (19.5\%) than in the USA $(29 \%)$ and England (30\%). SBP is higher in men than women in the younger age groups and becomes higher in women than men after age 60 years in Canada and age 70 years in England and the USA (24).

In a study in Turkey, the overall prevalence of HT was $39.5 \%$ in male, $41.6 \%$ in female and $40.9 \%$ in total (25).

We could not find any research for blood pressure measurement in physicians and nurses in the literature. Therefore, we can not compare our ratio according to the doctors and nurses in Turkey and other countries. Our hypertension rates was lower than the general population in Turkey and other countries. According to gender our hypertension rates were found about two times more in men.

According to study results lifestyle and dietary attitudes of health care workers were not as desired. As they are the role model for the rest of the population more time and care should be given to understand the reasons, so they may improve their attitudes regarding healthy diet and lifestyle.

Role of the funding source: The funding sources played no role whatsoever in design, planning, conducting, analyzing and interpreting the results, nor in the final draft and presentation of the data. 
Conflicts of interest: The authors had no conflicts of interest to declare in relation to this article.

\section{References}

1. May AM, Struijk EA, Fransen HP, et al. The impact of a healthy lifestyle on DisabilityAdjusted Life Years: a prospective cohort study. BMC Med. 2015; 13: 39.

2. Kirkegaard H, Johnsen NF, Christensen J, et al. Association of adherence to lifestyle recommendations and risk of colorectal cancer: a prospective Danish cohort study. BMJ 2010; 341: c5504.

3. Jiao L, Mitrou PN, Reedy J, et al. A Combined Healthy Lifestyle Score and Risk of Pancreatic Cancer in a Large Cohort Study. Arch Intern Med 2009; 169: 764-770.

4. Aleksandrova K, Pischon T, Jenab M, et al. Combined impact of healthy lifestyle factors on colorectal cancer: a large European cohort study. BMC Medicine 2014; 12: 168.

5. Chiuve SE, McCullough ML, Sacks FM, Rimm EB. Healthy lifestyle factors in the primary prevention of coronary heart disease among men: benefits among users and nonusers of lipidlowering and antihypertensive medications. Circulation 2006; 114: 160-167.

6. Chiuve SE, Rexrode KM, Spiegelman D, et al.Primary prevention of stroke by healthy lifestyle. Circulation 2008; 118: 947-954.

7. Hu FB, Manson JE, Stampfer MJ, et al. Diet, Lifestyle, and the Risk of Type 2 Diabetes Mellitus in Women. New Engl J Med 2001; 345: 790-797.

8. Gelber RP, Petrovitch H, Masaki KH, et al. Lifestyle and the Risk of Dementia in JapaneseAmerican Men J Am Geriatr Soc 2012; 60: 118 123.

9. WHO Expert Consultation. Appropriate bodymass index for Asian populations and its implications for policy and intervention strategies. Lancet 2004; 363: 157-163.

10. Sotiropoulos A, Gikas A, Spanou E, et al. Smoking habits and associated factors among Greek physicians, Elsevier, Public Health 2007; 121: 333-340.

11. Stamatopoulou E, Stamatiou K, Voulioti S, et al. Smoking Behavior Among Nurses in Rural Greece. Workplace Health \& Safety 2014; 62: 132-134.

12. Aryayev M, Lowe JB, Kuzmenko T. The prevalence of and knowledge about tobacco use among physicians in the Odessa region, Ukraine. Eur J Public Health 2014; 24: 474-476.
13. Oreskovich MR, Kaups KL, Balch CM, et al. Prevalence of alcohol use disorders among American surgeons. Arch Surg 2012; 147: 168174.

14. Ergör G. Chronic Diseases and Risk Factors Survey in Turkey.Ministry of Health Publication 2013; 909: 57-65.

15. Morishita Y, Miki A, Okada M, et al. Association of primary care physicians' exercise habits and their age, specialty, and workplace. J Multidiscip Healthc 2013; 6: 409-414.

16. Kim MJ, Son KH, Park HY, et al. Association between shift work and obesity among female nurses: Korean Nurses' Survey. BMC Public Health 2013; 13: 1204.

17. Mikail T. Working out (exercising) Habits of Physicians and Their Levels of Health in Life. SSTB International Refereed Academic Journal of Sports, Health \& Medical Sciences 2015; 15: p1226.

18. Puhl RM, Gold JA, Luedicke J, DePierre JA. The effect of physicians' body weight on patient attitudes: implications for physician selection, trust and adherence to medical advice. Int J Obes (Lond) 2013; 37: 1415-1421.

19. Flegal KM, Carroll MD, Kit BK, Ogden CL. Prevalence of obesity and trends in the distribution of body mass index among US adults, 1999-2010. JAMA 2012; 307: 491-497.

20. Shields M, Tremblay MS, Laviolette M, et al. Fitness of Canadian adults: results from the 2007-2009 Canadian Health Measures Survey. Health Rep 2010; 21: 21-35.

21. Bogossian FE, Hepworth J, Leong GM, et al. A cross-sectional analysis of patterns of obesity in a cohort of working nurses and midwives in Australia, New Zealand, and the United Kingdom.Elsevier, International Journal of Nursing Studies 2012; 49: 727-738.

22. Belgin Ünal. Chronic Diseases and Risk Factors Survey in Turkey. Ministry of Health Publication 2013; 909: 129-140.

23. WHO. World Health Organization, World Health Statistics 2012; http://www.who.int/gho/publications/world_he alth_statistics/2012/en/index.html (accessed Apr 2013).

24. Joffres M, Falaschetti E, Gillespie C,et al. Hypertension prevalence, awareness, treatment and control in national surveys from England, the USA and Canada, and correlation with stroke and ischaemic heart disease mortality: a crosssectional study. BMJ Open 2013; 3:e003423.

25. Sözmen K., Ergör G, Ünal B. Determinants of prevalence, awareness, treatment and control of high blood pressure. Dicle Medical Journal 2015; 42: 199-207. 